\title{
Does Cerclage wiring with Intramedullary Nailing in Subtrochanteric Fractures Improve the Final Outcome?
}

\author{
Rajendra Annappa ${ }^{1}$, Surendra Umesh Kamath ${ }^{2}$, Sunil Lakshmipura Krishnamurthy ${ }^{3}$, Sharan Mallya ${ }^{4}$, \\ Krithika Kamath ${ }^{5}$, Pooja Kundapur Suresh ${ }^{6}$ \\ ${ }^{1}$ Associate Professor, ${ }^{2}$ Professor and Head, ${ }^{3}$ Senior Resident, ${ }^{4}$ Assistant Professor, ${ }^{5}$ Medical student, Department \\ of Orthopaedics, ${ }^{6}$ Associate Professor, Department of Pathology, Kasturba Medical College, Mangalore, Manipal \\ Academy of Higher Education, Manipal, India
}

\begin{abstract}
Treatment of subtrochanteric fractures is challenging due to anatomical and biomechanical factors. Many methods have been suggested to achieve and maintain fracture reduction during operative fixation for subtrochanteric fractures. Open reduction and intramedullary fixation, clamp assisted reduction without cerclage wires and fracture reduction cables are suggested methods. We conducted a retrospective study to look for the results of subtrochanteric fractures managed by intramedullary fixation with or without cerclage wires. We reviewed all cases of subtrochanteric fractures operated with intramedullary fixation with long proximal femoral nail with or without cerclage wire fixation. All available data from patient's records available in medical records department were retrieved and evaluated. Statistical analysis were performed using SPSS software (v16). There were 86 cases of subtrochanteric fractures operated with intramedullary fixation at our Hospitals over a period of 5 years. Quality of fracture reduction of fractures are assessed good reduction was seen more often in cerclage group $64 \%$. Cerclage wiring was done in 14 cases. Nonunion was seen in 8 cases overall, 3 in cerclage group and 5 in non Cerclage group. Implant failure was seen in 3 cases in no cerclage group and 2 cases of cerclage group. We conclude that anatomical reduction is the key factor for successful outcomes. Closed reduction with good to acceptable reduction had better results. Cerclage wiring should be considered in selected cases where reduction is poor after open reduction.
\end{abstract}

Keywords: Subtrochanteric fractures, cerclage wiring, complications of subtrochanteric fractures

\section{Introduction}

Fractures occurring between lesser trochanter and isthmus of femur are treated as subtrochanteric fractures. Subtrochanteric femur fractures are also defined as fracture of the proximal femur with fracture line within $5 \mathrm{~cm}$ below the lesser trochanter. Treatment of these fractures is challenging due to anatomical and biomechanical factors. Flexion, abduction and external

\section{Corresponding author:}

\section{Dr Surendra Umesh Kamath}

Professor and Head, Department of Orthopaedics

Kasturba Medical College, Mangalore

Manipal Academy of Higher Education, Manipal, India. Phone - +919844275231

Email - surendra.kamath@manipal,edu rotation deformity due to strong muscular forces of Psoas, abductors and gluteal muscles ${ }^{1}$.

Adequate reduction and fixation is difficult even for experienced surgeons. These fractures are associated with high rate of complications due to deforming forces, decreased vascularity, instability and osteoporosis ${ }^{2}$.

Fixation options in these type of fractures include intramedullary nails, dynamic hip screws, dynamic condylar screws, proximal femoral locking plates ${ }^{3-6}$. Achieving anatomical reduction by closed methods is difficult in these fractures. The fracture comminution and anatomy of proximal femur makes it difficult for indirect fracture reduction techniques. Intramedullary fixation has been associated with better clinical outcomes and biomechanically higher fixation strength in previous studies $^{3-6}$. 
Many methods have been suggested to achieve and maintain fracture reduction during operative fixation for subtrochanteric fractures. Open reduction and intramedullary fixation, clamp assisted reduction without cerclage wires and fracture reduction cables are suggested methods ${ }^{7-11}$.

We reviewed subtrochanteric fractures managed by intramedullary fixation with or without cerclage wires and analysed the results with regards to quality of reduction, union and complications.

\section{Materials and Method}

We conducted a retrospective review of all cases of subtrochanteric fractures operated in our tertiary care hospital with intramedullary fixation with long proximal femoral nail (PFN,Matrix,India) or PFN Antirotation (Synthes,India) with or without cerclage wire fixation after obtaining approval for the study from institutional ethics committee. The study period was from August 2013 to August 2018. All cases with minimum 18 months follow up were included. The AO foundation/Orthopaedic trauma Association (AO/OTA) classification system was used to classify fractures.

All fractures which were situated within 2 inches $(5 \mathrm{~cm})$ from the lesser trochanter and fixed with intramedullary nail were included. Patients above 18 years below 75 years, isolated subtrochanteric fractures with configuration amenable to cerclage wiring like long oblique, spiral, were included

Patients below 18years, pathological fractures, open fractures, fractures sustained in patients treated with bisphosphonates, previous surgeries around hip and segmental fractures were excluded.

All available data from patient's records available in medical records department were retrieved and all available radiographs and clinical data were evaluated. Patients with data available for minimum 18 months were included. Major complications were identified and documented. These included non-union, infection, implant failure and return to surgery. The quality of reduction was assessed as good (both maximum cortical displacement $<4 \mathrm{~mm}$ and angulation $\leq 10^{\circ}$ ), acceptable (either maximal displacement $<4 \mathrm{~mm}$ or angulation $\leq 10^{0}$ ) or poor (maximum cortical displacement $\geq 4 \mathrm{~mm}$ and angulation $>10^{\circ}$ ).

Statistical analysis were performed using SPSS software (v16). Data were analysed using mean and standard deviation for continuous and categorical data respectively. Chi square test was used for categorical variables and analysis of variance (ANOVA) was used to compare continuous variables. Statistical significance was significant when $\mathrm{p}$ value was $<0.05$.

\section{Results}

We could identify 86 cases of subtrochanteric fractures for the period August 2013 to Aug 2018 operated with intramedullary fixation at our hospitals. Of them 55 met the inclusion criteria of our study. Mean age of the patients include in the study was 56.4 years and low velocity injuries were seen in $55 \%$ of the patients. Open reduction of the fractures was performed in 30 patients. Cerclage wiring was done in 14 cases. Cerclage wiring was used with cases treated with open reduction.

When quality of fracture reduction of subtrochanteric fractures are assessed good reduction was seen in 33\% of the cases and more often in cerclage group $64 \%$ but was not statistically significant (Fig 1). Varus reduction was more frequently seen contributing to $29 \%$ of the cases and mostly when no cerclage was done. Of the 55 cases 18 cases were re operated again 10 of them were implant removal without complications and 8 cases were revised due to complications. There was no reported complications of passage of cerclage wire (Table 1)

Nonunion was seen in 8 cases overall, 3 in cerclage group and 5 in non Cerclage group. Implant failure was seen in 3 cases in no cerclage group and 2 cases of Cerclage group (Fig 2). Deep infection was seen in 2 cases each in both group and superficial infection in one case in no cerclage group which healed with antibiotics. Open reduction was done in all cases where infection was recorded (Table 1). 
Table 1: Outcomes of subtrochanteric fracture fixation

\begin{tabular}{|l|l|l|l|l|}
\hline & Total & No Circlage & Circlage & P value \\
$\mathrm{N}=51$ & $\mathrm{~N}=14$ & \\
\hline $\begin{array}{l}\text { Quality of } \\
\text { Reduction (\%) }\end{array}$ & $\begin{array}{l}\text { Good=18(32.7) } \\
\text { Acceptable=26(47.3) } \\
\text { Poor=11(20) }\end{array}$ & $\begin{array}{l}\text { Good- 9(22) } \\
\text { Acceptable=23(56) } \\
\text { Poor-9(22) }\end{array}$ & $\begin{array}{l}\text { Good=9(64.2) } \\
\text { Acceptable=3(21.4) } \\
\text { Poor=2(14.2) }\end{array}$ & 0.848 \\
\hline $\begin{array}{l}\text { Varus } \\
\text { Reduction }\end{array}$ & $16(29 \%)$ & $15(36.6 \%)$ & $01(7 \%)$ & 0.066 \\
\hline Infection & $4(7.2 \%)$ & $2(4.8 \%)$ & $2(14 \%)$ & 0.530 \\
\hline Nonunion & $8(14.5 \%)$ & $5(12 \%)$ & $3(21 \%)$ & 0.653 \\
\hline
\end{tabular}

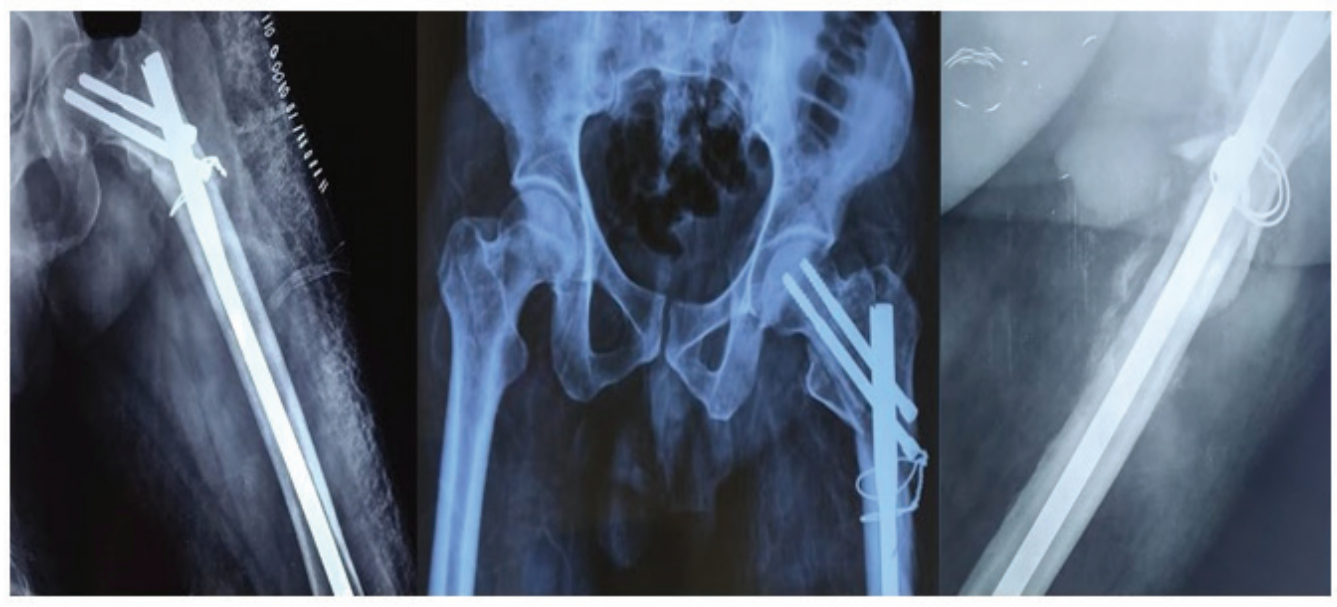

Figure 1: Good reduction and union in circlage grou

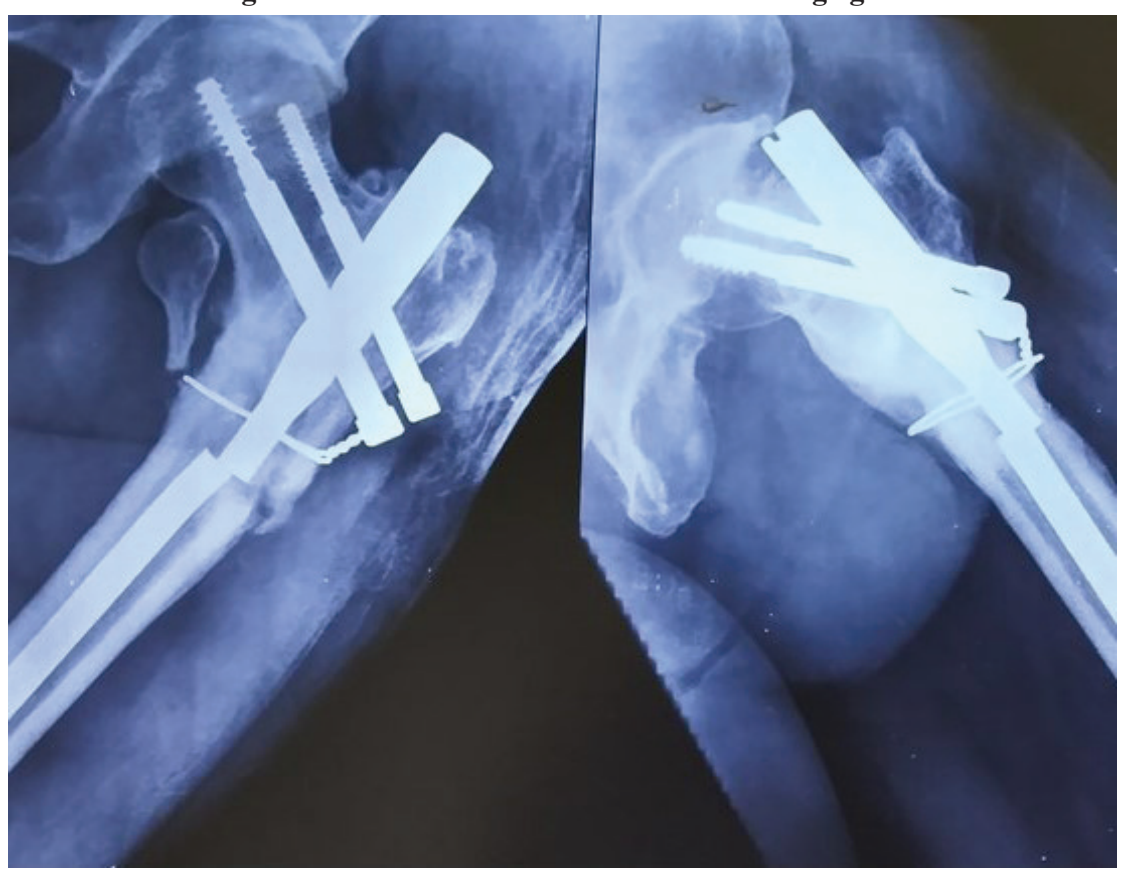

Fig 2 a Complications in Circlage group - non-union with implant failur 


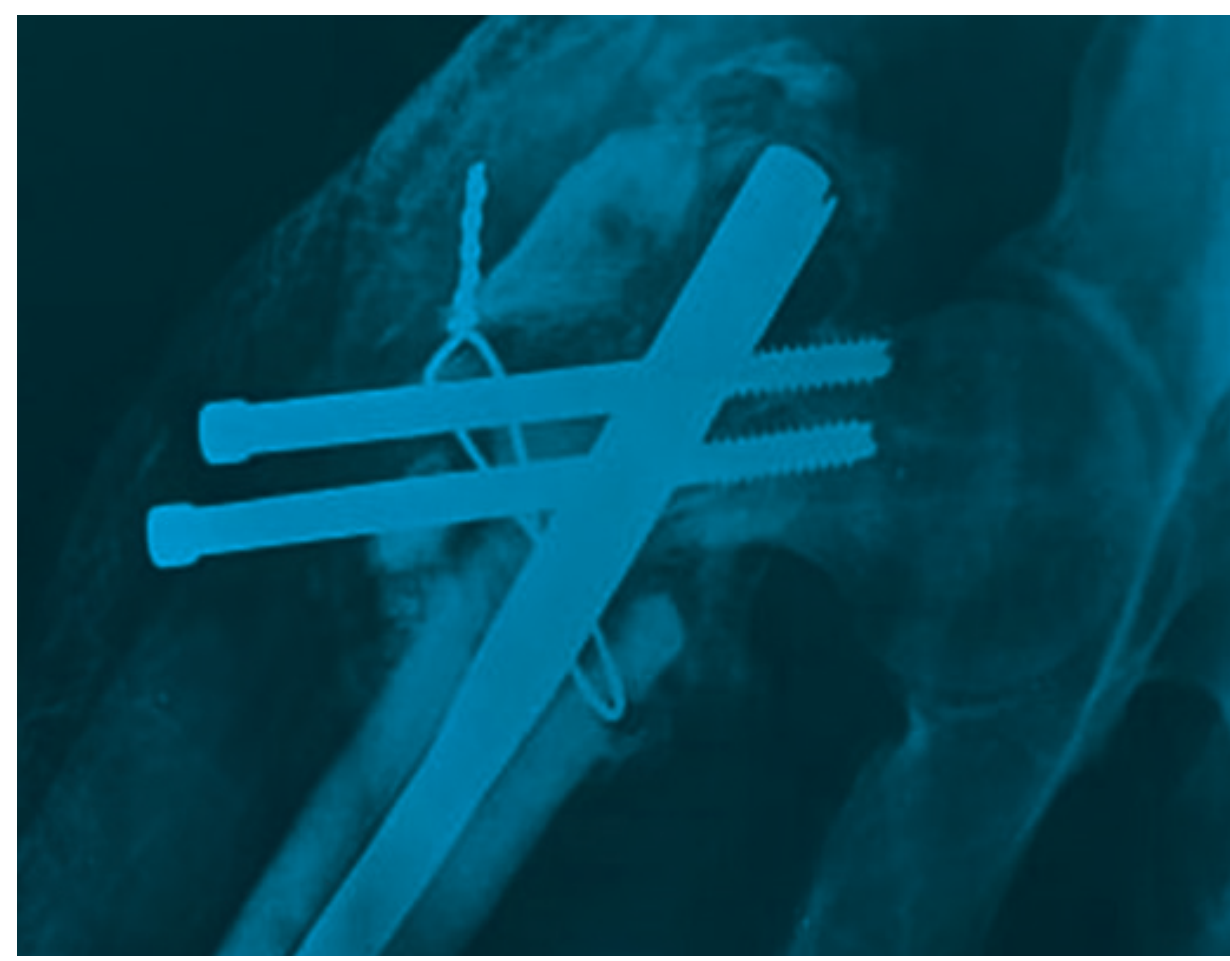

Fig 2b Complications in Circlage group - implant failur

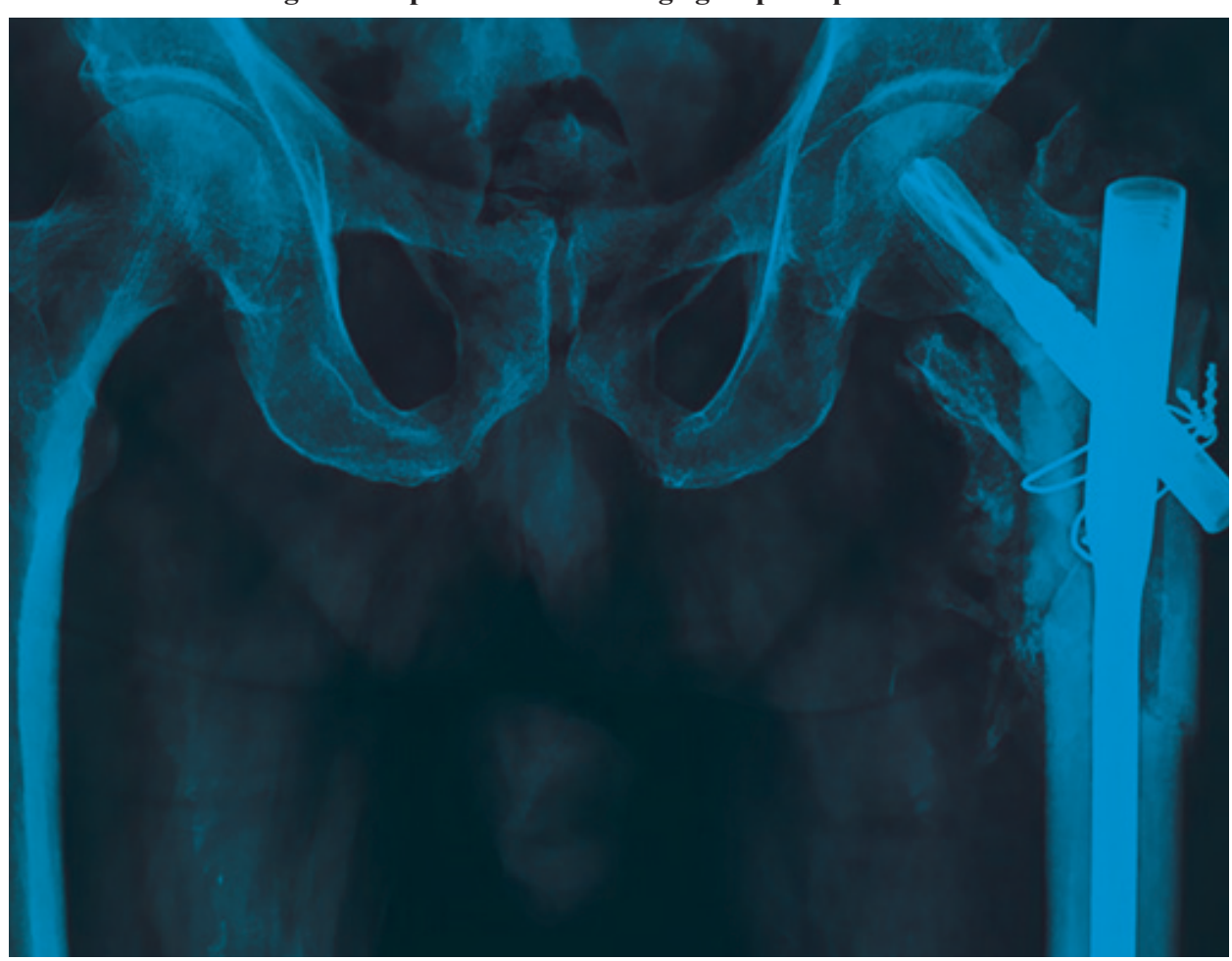

Fig 2c Complications in Circlage group - Infectio

\section{Discussion}

Subtrochanteric fractures more often required open reduction for better anatomical reduction. Rates of nonunion and revision surgery are determined by anatomical reduction intraoperatively. Anatomical reduction was key factor which results in early union and better functional outcomes. Cerclage wire fixation results in better reduction but is associated with few complications. In our study cerclage wiring was associated with complications like non-union and infection. Fractures managed with a 
cerclage wire to augment intramedullary nail had less fracture displacement, less fracture angulation and improved quality of fracture reduction.

Subtrochanteric fractures require open reduction which has been reported in literature between $7-40 \%$. Closed reduction preserves fracture hematoma and periosteal blood supply. But due to deforming forces achieving correct entry point is difficult. Minimal open reduction and maintaining with a reduction clamp ${ }^{7}$ and intramedullary fixation has resulted in good functional outcomes and union. Judicial usage of cerclage wire has been recommended with minimal soft tissue disruption. Open reduction was done in 53\% of our cases and in all cases of cerclage wiring and we could achieve good to acceptable reduction in $80 \%$ of cases ${ }^{12}$.

Varus reduction results in poor functional outcomes, delayed and non-union ${ }^{12-14}$ Varus reduction was present in all cases of non-union in our study. Cerclage wiring results in correcting varus reduction. With the cerclage wire passer, technique is simple and is not associated with any complications. The biomechanical advantage of cerclage wire has been studied and there was reduced varus deformation and cut out of proximal screws on cyclical loading. This is possible due to preservation of medial buttress and reducing fracture stress on lateral side 15. Cerclage wiring being more invasive, was assumed to result in decreased blood supply to bone and fracture and eventually non-union but recent studies have suggested vascularity is preserved ${ }^{16}$. Every attempt should be made to preserve soft tissues and cerclage wiring with minimal soft tissue damage.

The limitation of the study was it was retrospective. All the data available were accumulated from patient's files and systematically reviewed. There was limitation in identifying all complications those who presented in other hospitals. Cerclage wiring technique could not be assessed for each surgery which may involve more soft tissue damage. Sample size was not adequate in detailed statistically analysis. Short term clinical and functional outcomes could not be assessed.

\section{Conclusion}

We conclude that anatomical reduction is the key factor for successful outcomes. Closed reduction with good to acceptable reduction had better results. Cerclage wiring should be considered in selected cases where reduction is poor after open reduction.

Acknowledgement: Manipal Academy of Higher Education, Manipal, Kasturba Medical College, Mangalore and its constituent hospitals for offering this opportunity to conduct this research.

\section{Conflict of Interest - Nil}

\section{Source of Funding - Nil}

Ethical Clearance- Taken from Institutional Ethics Committee

\section{References}

1. Lundy D W. Subtrochanteric femoral fractures. J Am Acad Orthop Surg.2007; 15:663-71

2. Bedi A, Toan Le T. Subtrochanteric femur fractures. Orthop Clin N Am.2007; 35(4):473-83.

3. Hoskins W, Bingham R, Joseph S, Liew D, Love D, Bucknill A et al. Subtrochanteric fracture: The effect of circlage wire on fracture reduction and outcome. Injury. Int. J. Care Injured.2015;46: 1992-95.

4. Matre K, Havelin LI, Gjertsen JE, Vinje T, Espehaug B, Fevang JM.Sliding hip screw versus IM nail in reverse oblique trochanteric and subtrochanteric fractures. A study of 2716 patients in the Norwegian Hip Fracture Register. Injury.2013;44(6)735-42.

5. Forward DP, Doro CJ, O'Toole RV, Kim H, Floyd JC, Sciadini MF, et al. A biomechanical comparison of a locking plate, a nail, and a 95 angled blade plate for fixation of subtrochanteric femoral fractures. J Orthop Trauma. 2012;26(6):334-40.

6. Burnei C, Popescu G, Barbu D, Capraru F. Intramedullary osteosynthesis versus plate osteosynthesis in subtrochanteric fractures. J Med Life. 2011;4(4):324-329.

7. Mingo Robinet J, Torres-Torres M, MorenoBarrero M, Alonso J A, García-González S. Minimally invasive clamp-assisted reduction and cephalomedullary nailing without cerclage cables for subtrochanteric femur fractures in the elderly: surgical technique and results. Injury, Int. J. Care Injured 2015; 46: 1036-1041.

8. Kim JW, Park KC, Oh JK, Oh CW, Yoon YC, Chang HW. Percutaneous cerclage wiring followed by intramedullary nailing for subtrochanteric 
femoral fractures: a technical note with clinical results. Arch Orthop Trauma Surg. 2014 Sep; 134(9):1227-35

9. Beingessner DM, Scolaro JA, Orec RJ, Nork SE, Barei DP. Open reduction and intramedullary stabilisation of subtrochanteric femur fractures: a retrospective study of 56 cases. Injury. 2013 Dec; 44(12):1910-5.

10. Tomás J, Teixidor J, Batalla L, Pacha D, Cortina J. Subtrochanteric fractures: treatment with cerclage wire and long intramedullary nail. J Orthop Trauma. 2013; Jul;27(7):e157-60.

11. Ban I, Birkelund L, Palm H, Brix M, Troelsen A. Circumferential wires as a supplement to intramedullary nailing in unstable trochanteric hip fractures: 4 reoperations in 60 patients followed for 1 year. Acta Orthop.2102;83(3):240-243..

12. Afsari A, Liporace F, Lindvall E, Infante A Jr, Sagi HC, Haidukewych GJ. Clamp-assisted reduction of high subtrochanteric fractures of the femur: surgical technique. J Bone Joint Surg Am.2009; Aug; 91(8):1913-8. doi: 10.2106/JBJS.H.01563.

13. Haidukewych GJ, Berry DJ. Nonunion of fractures of the subtrochanteric region of the femur. Clin Orthop Relat Res. 2004; 419:185-8.

14. Shukla S, Johnston P, Ahmad MA, WynnJones $\mathrm{H}$, Patel AD, Walton NP. Outcome of traumatic subtrochanteric femoral fractures fixed using cephalo-medullary nails. Injury.2007; 38(11):1286-93.

15. Müller $\mathrm{T}$, Topp $\mathrm{T}$, Kühne $\mathrm{CA}$, Gebhart $\mathrm{G}$, Ruchholtz S, Zettl R. The benefit of wire cerclage stabilisation of the medial hinge in intramedullary nailing for the treatment of subtrochanteric femoral fractures: A biomechanical study. Int Orthop.2011; 35(8):1237-43.

16. Apivatthakakul T, Phaliphot J, Leuvitoonvechkit S.(2013) Percutaneous cerclage wiring, does it disrupt femoral blood supply? A cadaveric injection study. Injury.2013;44(2):168-74. 